\title{
PAPER
}

\section{Terrorism, racism, speciesism, and sustainable use of the planet}

\author{
John Cairns, Jr.* \\ Department of Biology, 1020 Derring Hall, Virginia Polytechnic Institute and State University, \\ Blacksburg, Virginia 24061, USA
}

\begin{abstract}
The 11 September 2001 attacks on the World Trade Center in New York City and the US Pentagon in Washington, DC have seized our attention and undermined our sense of security. These terrorist actions showed a contempt for other persons and their beliefs and practices. They are extreme demonstrations of a feeling of superiority which ignores the inherent worth of life by killing or wounding some and depriving others of resources that improve their quality of life. In this respect, terrorism is similar to racism and speciesism in that all are expressions of feelings of superiority over other life forms and that all are incompatible with sustainable use of the planet. It is proposed that both terrorism and racism have their genesis in speciesism. Sustainability requires a mutualistic relationship between humans and the millions of other species that collectively constitute the planet's ecological life support system. It further requires enhancement and protection of natural capital, as well as the enhancement and protection of the technological and economic life support systems that depend upon natural capital. Both terrorism and racism endanger the fair and equitable allocation of resources and the quality of human life of present and future generations. This is probably both the cause and effect of resource allocations. However, to achieve sustainable use of the planet, humans must acknowledge the inherent worth of other life forms. There is no guarantee that abolishing terrorism, racism, and speciesism will enable human society to achieve sustainable use of the planet; however, it is difficult to envision achieving sustainability if they persist.
\end{abstract}

KEY WORDS: Terrorism · Sustainable use of the planet · World peace $\cdot$ Sustainocentric dynamics Resource wars

Resale or republication not permitted without written consent of the publisher

Shall I not inform you of a better act than fasting, alms, and prayers? Making peace between one another: enmity and malice tear up heavenly rewards by the roots.

Muhammad

\section{DISRUPTERS}

Terrorism, racism, and speciesism are disrupters that might well destroy everything human society purports to value (e.g. a quality life) and possibly even the human species. New ways have emerged for the 'powerless' to inflict major damage on the 'powerful.'

*Email: jcairns@vt.edu
Disrupters can damage severely both the infrastructure and morale of powerful nations at a relatively low cost to the perpetrators, although some of them lose their lives in the process. Threats to large suspension bridges and nuclear power plants have had significant disruptive effects, even without being implemented.

Although human society has made some ethical progress in the last century, it is far from achieving a universal ethos (a guiding set of values). However, technical progress in weaponry has been remarkable 
during the same period, and dependence upon the technological life support system has become even greater as cities' populations have increased dramatically. However, with sufficient commitment to sustainable use of the planet, the efforts to instigate rage and fanaticism can be rendered less effective. There is, after all, nothing inevitable about the present escalation of violence. This novel situation requires a creative and far reaching response that is constructive rather than destructive. Achieving sustainable use of the planet seems to be better suited to this purpose than war or counter-terrorism.

\section{PEACE AND SUSTAINABILITY}

Peace is a necessary prerequisite for sustainable use of the planet, but not a guarantee that it will be achieved (Cairns 2000). War is a profligate user and destroyer of resources, and sustainability requires both protection and accumulation of natural capital. The latter requires that peace exist not only among humans but also with the biosphere and the millions of species it contains.

Terrorism, racism, and speciesism are all based on a feeling of superiority of 'us' over 'them.' Arguably, racism and terrorism had their genesis in human feelings of superiority over other life forms, which have been extended to include other members of the human species as well. Since the genetic makeup of all humans is extraordinarily similar, racism cannot be justified by genetic makeup (Ehrlich 2000).

Unquestionably, human genetic makeup differs considerably from the $30+$ million other species on the planet. However, most of the services that these other species provide (albeit unintentionally) cannot be replaced by human technology (Hawken et al. 1999). Further, new technology enabled humans to usurp the vast supply of unexhausted resources and develop still unoccupied (by humans) areas of the planet (Ward 1973). However, the redistribution of resources among humans (via taxation, welfare, and insurance) has not had much effect upon the increasingly disparate wealth among humans, as evidenced by the increasing range in sizes of ecological footprints (Wackernagel \& Rees 1996).

The ecological footprint in hectares per person is 5.1 in the US, 1.8 for the world as a whole, and 0.4 in India. It is worth emphasizing that there is no strong correlation between quality of life attributes that humans profess to cherish and the size of the ecological footprint. For example, Kerala, a southern Indian state, has a per capita income of about US\$1/day, but life expectancy, infant mortality, and literacy rates are similar to those of industrialized countries. Such attributes as a sense of community are difficult to quantify, but they might well be higher in less industrialized areas than in countries with a large ecological footprint, since acquiring and caring for material possessions does significantly reduce time for family, friends, and reflection. Wackernagel \& Rees (1996) conclude that Kerala's exceptional standard of living, coupled with a small ecological footprint, is based more on accumulated social capital than on manufactured capital.

Terrorism increases the size of the ecological footprint both per capita and per nation (defensive measures) without increasing life quality. Racism attempts to justify inequity and unfairness in access to resources. Both terrorism and racism are based on feelings of superiority over other members of Homo sapiens, and both affect equity in resource utilization. If human society does not protect and accumulate natural resources (natural capital) and uses the existing resources at an unsustainable rate, solutions to terrorism and racism will not markedly benefit future generations because inadequate resources will make life very difficult or impossible.

\section{HOMOCENTRIC VS ECOCENTRIC}

Rowe's (1999/2000a,b) book reviews of Consilience (Wilson 1998) and The Ecology of Eden (Eisenberg 1998) illustrate part of the homocentric vs ecocentric dichotomy. Rowe believes that Wilson views all things through the lens of science and devalues other lenses or perspectives. I believe that if one adds Wilson's other books such as Biophilia (Wilson 1984) or The Biophilia Hypothesis (Kellert \& Wilson 1993) and the human tendency to focus on all life forms as a biologically based need, then the various perspectives (psychological, biological, cultural, symbolic, aesthetic) clearly emerge. Collectively, these constitute far more than a scientific 'lens' or narrow perspective. Most importantly, Wilson's unifying theme is that humans are a part of, not apart from, ecosystems (i.e. ecocentric). As Rowe notes, Eisenberg is homocentric - the world and its biosphere exist for humans who are 'the crown of creation.' The Earth Spirit Rising followers of theologian Thomas Berry assert that the world does not exist except through the eyes of humans and that humans are the culmination of the evolutionary process. Very few evolutionary biologists would subscribe to this concept.

Publications on sustainable development (e.g. World Commission on Environment and Development 1987) are centered on indefinite occupancy of the planet by human society. However, I believe that sustainable use (rather than development) of the planet is a better description of a realistic goal, i.e. the use envisioned is 
by human society in the context of a mutualistic relationship with natural systems (e.g. Cairns 1997). Arguably, a mutualistic relationship acknowledges an interdependence and diminishes, but does not eliminate, the feeling of human superiority over other life forms. This concept is ecocentric in that human behavior would be modified to preserve and enhance ecological integrity, but is homocentric in that the primary benefit of sustainability is indefinite use of the planet by Homo sapiens.

\section{ONE SPECIES, ONE GOAL}

The primary goal of sustainable use of the planet is indefinite use by future generations of humans. No publications on sustainability specify restricted use by any ethnic, religious, or other category of the human species. It could not be otherwise! The quest for sustainable use of the planet will require the combined efforts of all human society, and this goal will only be possible if all have a hope for a quality life for their descendants. The goal may not be achieved even if terrorism and racism are markedly reduced, but, if they continue at present levels, sustainability will remain beyond human society's reach.

\section{REDEFINING TERRORISM}

The Random House Dictionary defines terrorism as the use of violence and threats to intimidate or coerce. This definition clearly is limited to members of the human species and perhaps a limited number of other species. The terrorist actions in the US in September 2001 deprived many people of their lives, physically injured others, left an entire nation in severe trauma, and caused severe property damage (i.e. loss of human habitat). However, in the same vein, economic development of human society kills or injures individuals of other species and deprives them of essential habitat. Depriving other life forms of habitat necessary for their survival is neither an attempt to intimidate or coerce. However, in terms of their potential for survival, it is far more devastating than damage to human artifacts (property) that can, and undoubtedly will, be replaced. As a consequence, I have included habitat loss of other species under terrorism despite the very evident semantic problems. A new word is needed!

It would be a dreadful mistake to commit the common error of anthropomorphosis when thinking about the cognitive abilities of other animals. Hauser (2000) has persuasively demonstrated that animals do have complex mental operations well adapted to the ecological niches they occupy. The inevitable conclusion is that habitat destruction and fragmentation must be psychologically disturbing to a significant number of species. For migratory species, the loss of habitat used for many generations must certainly be disturbing. Additionally, many humans have witnessed 'road kills' as animals unsuccessfully attempt to move from one part of their range to another over a road. Even though the word terrorism may be inappropriate, since there is usually no intent to intimidate or coerce, the results are quite similar - human society has deprived other life forms of life and habitat.

\section{RELATIVE RISKS}

In the US, far more individuals are killed or injured annually by gunshots or drunken drivers than were killed or injured in the 11 September terrorist attacks. However, the emotional and political response was orders of magnitude greater on 11 September. Of course, when deaths occur daily from less spectacular causes, the aggregate numbers are not the attention grabbers they would be if all the deaths occurred in one day in one or two places.

The risks of massive deaths due to famine and dislocation because of global warming are also quite large and should not be ignored. Risk management is a multidimensional activity. Sustainable use of the planet involves risks (Orvos \& Cairns 1998) and will fail if only certain risks, such as terrorism, get a disproportionate amount of attention.

\section{SUSTAINOCENTRIC DYNAMICS}

Sustainable use of the planet requires the comingling of global, regional, and local perspectives. For example, global warming requires a planetary perspective. Pulliam's (1988) ecological 'source/sink' model requires a bioregional approach. In this model, some habitats become sources from which surplus populations migrate to less suitable habitats that act as sinks for the surplus population. Sources can become sinks and sinks can become sources if the area and temporal span of the study are large. At a local level, ecological restoration is essential whenever damage occurs so that the source/sink balance is not disrupted.

Both local and bioregional dynamics are difficult, but not impossible, to model and predict. At the global level, misjudgments will be exceedingly costly and possibly fatal to human society. Of course, one can always make the case, as Eisenberg (1998) does, that humans are a product of nature and what they do is 'natural.' However, destroying the habitat of other species and driving many of them to extinction does 
not correspond to the human compassion and sympathy of society displayed on 11 September 2001 for victims' families. Destroying the habitat of other species on a massive scale is a dysfunctional relationship rather than a healthy, mutualistic one. As Eisley (1970) notes, such a mutualistic relationship must involve the full range of human abilities, interests, and values, especially those that are cultural achievements. Three decades ago, Caldwell (1972) listed some immediate steps that had developed over at least a century and had, he then thought, become too obvious to ignore. It seems increasingly likely that some crucial environmental threshold will have to be crossed and result in an impact that will affect all human society as the 11 September 2001 terrorist attack appears to have had on the US. By definition, sustainable use is permanent use and, thus, a sustainocentric position must last, not for a few months, years, or even centuries. Since the ecological life support system is dynamic, the relationship of human society with natural systems must also be dynamic and will require continuous informed judgment and modification of behavior. A central question is 'What evidence will be required to induce a significant behavioral change in human society?'

\section{THE THRESHOLD PROBLEM}

The 11 September 2001 terrorist attacks in the US provided some interesting information on the damage level needed to elicit a marked shift in the response of politicians and the general public to terrorism. Earlier attacks on US embassies and the U.S.S. Cole (both abroad), the Oklahoma bombing of a US federal building, and even the first bombing of the World Trade Center in New York City did not result in a major paradigm shift in the US's anti-terrorist activities. The 11 September attacks did, although the durability of the shift will not be proven for a number of years. The global response to the 11 September events is far less certain in both the short and long term.

The crossing of a threshold that would result in disequilibium of the planet's ecological life support system will neither be detected as easily nor, because of the complexity of the biosphere, be as easily understood by politicians and the general public. It is probable, not just possible, that a major ecological threshold could be crossed without anyone, even scientists, being aware of it, as there are serious problems in detecting thresholds, even at lower levels of biological organization (Cairns 1992). The simulation of biospheric thresholds is problematic but will doubtless improve if surveillance of the biosphere is undertaken in a systematic and orderly fashion. Even when such information is improved, it will be essential to remem- ber that each threshold is variable because it is embedded in a multivariate system that affects it. Meadows et al. (1992) has a superb discussion of this issue. But, as Meadows (2001) writes, overshoot does not mean collapse, and material and energy throughout the world must be cut, but not people, not living standards, not the dream of a better world.

\section{RECRUITS FOR TERRORISM}

Arguably, overpopulation with its concomitant large numbers of idle young who are searching for a meaning to life produces a few individuals willing to give their lives to strike at the perceived enemy. The rapidly increasing gap between the 'haves' and 'have nots' exacerbates the problem. It should come as no surprise that Afghanistan, one of the poorest countries of the world with a high birth rate, should host terrorists and permit training camps. As long as breeding grounds for terrorists exist, there will always be people to incite the emotional youth and 'masterminds' to train and organize them.

Since 11 September 2001, CNN and other international news organizations have had numerous programs depicting how terrorists and their families are honored and respected in some countries. Terrorists' families are cared for financially and the terrorists' pictures and names are prominently displayed on public thoroughfares in cities, museums, and the like. Any society that respects and honors terrorists will inevitably be a breeding ground for them. Youth can achieve a status otherwise unavailable to them and simultaneously bring honor and even financial rewards to their families. Terrorists are cheered on by multitudes who are unwilling to take such drastic measures. The more horrific the terrorist acts, the easier it seems to obtain new recruits. The important issue is that underlying all of this is a feeling of superiority because God is on their side.

\section{THE ROLE OF RELIGION}

Dubos (1972) remarks that, as a member of an international team preparing a report (Only One Earth: The Care and Maintenance of Our Small Planet), he had to think in global terms, i.e. each part of the planet is interacting with all other parts and each earthling belongs to the family of man. Dubos affirms that these two attitudes are not incompatible but are, in fact, complementary. He believes that, from family to clan, from clan to nation, and from nation to federation, enlargements of allegiance have occurred throughout history without weakening the earlier loves. Dubos' 
key concept is that humans can develop a loyalty to planet Earth while maintaining an emotional attachment to both their countries and cultural diversity. It is exceedingly difficult to believe in sustainable use of the planet in these chaotic times, with terrorism, racism, and monumental biotic impoverishment, but the alternative is unthinkable because it reflects a picture of the human species that will be difficult to face. Appeals to reason are easy to make but difficult to implement. Reason shows that destroying the planet's ecological life support system and each other is not a sustainable way to live. Sustainability is both a social and an ecological problem, with human society's relationship with natural systems at its core.

Similarly, if religions wish to survive, human society must learn to live sustainably. Religious leaders who fail to chastise those who chant 'death to America' or who rejoice in the events of 11 September 2001 are morally bankrupt as are all cults based primarily on hate. Religious leaders who remain silent when natural systems are destroyed and species driven to extinction are no better because neither posture favors sustainability. Tucker \& Grim (2001) assert that there is an emerging alliance between world religions and ecology: (1) no one religious tradition has a privileged ecological perspective; (2) although religions are necessary partners in the current ecological movement, they are not sufficient without the indispensable contributions of science, economics, education, and policy; (3) there is frequently a disjunction between principles and practices - ecologically sensitive ideas in religions are not always evident in environmental practices of particular civilizations; and (4) religions have all too frequently contributed to tensions among ethnic groups.

In The Descent of Man, Darwin (1871) confronted the apparent evolutionary anomaly of ethics. From an evolutionary viewpoint, the most ruthlessly selfish individuals would find more success in the competition for mates and resources and, thus, would transmit their traits to their descendants. In short, 'goodness' may be quite fatal to an individual practicing it. Darwin addressed this issue by noting that membership in a closely knit society, which can only exist if its members refrained from antisocial conduct, selects for 'goodness.' Sustainable use of the planet merely expands this view to a global level, which includes other species, humans, and their descendants (Callicott 2001). The present vast potential for nuclear, biological, and chemical warfare will put Darwin's hypothesis to a severe test. In terms of the events in 2001, Leopold's (1949) observation - that ecology simply enlarges the boundaries of the community to include soils, water, plants, and animals - is astonishingly accurate.

\section{ISOLATING MECHANISMS}

Terrorism, racism, and speciesism are isolating mechanisms based partly, arguably primarily, on a feeling of superiority to other life forms. As Ehrlich (2000) remarks, humans are small-group animals trying to live in gigantic groups in an increasingly impersonal world in which individual natures are based on ever smaller fractions of society's culture. Ehrlich notes that humans will never deal with the devils in the details unless they see the big picture. In an era of specialization, the big picture is exceedingly difficult to see. Even the educational systems have developed isolating mechanisms (Cairns 1993) that keep disciplines apart, although the mechanisms are less formidable than they once were (Cairns 1999). However, over two decades ago, Kahneman (1980) remarked that the increase in humans' power over the environment had not been accompanied by a concomitant improvement in the ability to make rational use of that power. While conscious evolution can be accelerated by shocks (e.g. 11 September 2001), the threshold needed to have an effect might require millions of human deaths and far greater loss of other life forms. A biospheric collapse will be costly and more difficult, perhaps impossible, to repair. Perhaps then an office of planetary security would be created, hopefully in time to take preventative action.

\section{HISTORY VS CONSCIOUS EVOLUTION}

Durant \& Durant (1968) make three important observations about biology and history. (1) Life is competition, which may be peaceful when food abounds but violent when the mouths outrun the food (in the 21st century, it seems appropriate to substitute the word resources, including food, for the word food alone). (2) Life is selection, and some individuals are better equipped than others to meet the tests of survival. Since Nature (defined as total reality and its processes) has not read very carefully the US Declaration of Independence or the French Revolutionary Declaration of the rights of man, humans are all born unfree and unequal. Durant \& Durant note that inequality is not only natural but that it increases as the complexity of civilization increases. (3) Life must breed. Nature has a passion for quantity as a prerequisite to the selection of quality. Nature is more interested in the species than in the individual and makes little distinction between civilization and barbarism.

These ideas are exceedingly difficult to place in a sustainability context. As McNeill (2000) notes, the enormity of ecological change in the 20th century indicates that in the 21st century history and ecology 
must be viewed concomitantly. He writes that modern history is written as if the planet's ecological life support systems were stable (which they are not) and are present only as a backdrop to human affairs. Similarly, the field of ecology should incorporate the dynamics of historical change and the complexity of social forces. As the events of 11 September 2001 and the anthrax scares that followed clearly demonstrate, human society has a choice between making the major societal and individual choices that might lead to sustainable use of the planet or valiantly trying to maintain the status quo and risking one or more global catastrophes.

Ehrlich (2000) remarks that there is no easy formula for understanding the human past or today's human nature or for projecting the human future. He notes that cultural evolution has resulted in the extinction of many past civilizations and that the present global civilization had better move rapidly to modify its cultural evolution and cope with its deteriorating environmental circumstances before it runs out of time. This challenge is daunting because society and its scientists have only a dim idea of the ultimate consequences of the environmental changes that have already occurred. If one adds the increased scale of terrorism and the costs of reducing it and repairing the damage, even the most optimistic individuals must have some doubts about the effectiveness of present activities and how they will affect the progress toward sustainable use of the planet. For example, disruption in oil production might either hasten development of alternative sources of energy or result in more conflict. The divisiveness caused by terrorism, religious extremism, racism, speciesism, and ethnic conflict is all the more troubling when global society may be approaching crucial ecological thresholds more rapidly than previously thought.

\section{DESIGN WITH NATURE}

Nature favors quantity and from that quality is selected. Quality in these terms are components (i.e. species) that have a mutualistic relationship with the interdependent web of life. Over billions of years, this system resulted in the accumulation of much natural capital, although there were 'downturns' resulting from climatic change and concomitant extinction of species. In fact, the exponential growth of the planet's human population has been possible because of this accumulated natural capital (e.g. petroleum, coal, fossil water, topsoil, old growth forests, and the like). In addition, technology has not only enabled humans to harvest natural resources faster than their replacement rate but has also markedly reduced the threat of disease and health problems in general, which, together with increased resources per capita, have supported the expansion of the human population. However, continuation of this population growth is only possible if the governing conditions are reasonably stable, which is increasingly unlikely. Developed countries are dependent upon inexpensive energy, relatively stable climate, rapid economic growth, and, above all, reasonably stable social conditions. In an era when there are weapons readily available to discontented and enraged individuals, stable social conditions are problematic. Unfortunately, societal catastrophes diminish concern for the ecological life support system, which is still being taken for granted. Attitudes and behaviors can be dramatically altered by catastrophic events, and one wonders how devastating the ecological 'wake up' call will be and how resilient human society will be if it occurs before the terrorist and racist problems are significantly resolved.

How much optimism that these social problems will be satisfactorily resolved is justified? Emlen (1995) speculates that humans possess a set of biologically based predispositions for interfacing with one another. Sustainable use is based on the assumption (faith) that human society will ultimately select rational solutions to societal problems, despite massive evidence to the contrary. Regrettably, many people tend to seek answers to terrorism, racism, speciesism, and other issues impeding the quest for sustainability in ways that circumvent rational analysis. Ehrlich (2000) believes that an initial step in resolving some of the human predicaments is the creation of a more deliberate style of cultural evolution - one that would direct change in a variety of ways more beneficial to most human beings. However, Ehrlich cautions that biological evolution did not equip hominid ancestors with a desire to address gradual changes in their environmental niche because they were then not capable of detecting or influencing such alterations.

For example, human society in developed countries is even now hostage to countries that supply petroleum. Within countries such as the US, which have major traffic congestion, more highways are being built despite the persuasive evidence that attempts to relieve the problem actually exacerbate it (e.g. Freund \& Martin 2001). More energy efficient public transportation would not only alleviate this problem but should also reduce greenhouse gases. Public transportation might be more vulnerable to terrorist attack, but it would also put society on the path to sustainability. This illustration is just one example of the issues that should be widely discussed in the quest for sustainability. Loss of individual transportation would require changes in behavior but would probably increase long-term security. Of course, the automobile is not the only artifact requiring oil, but it is the one 
most closely associated with individuals and, therefore, symbolic of the dominant automobile culture in the US. Billions of dollars have been spent on 'star wars' defense - a technology with highly uncertain results. If an equivalent amount were to be spent on alternative power sources (e.g. fuel cell engines, wind and solar power), the US would be far less dependent on Middle East oil and less likely to become embroiled in its wars. If terrorists succeed in destabilizing the present Middle East governments, many lives will be lost as a consequence of the refusal to give alternative energy sources a high priority. Failure to develop sustainable alternative energy sources places the entire world at risk and impedes the transition to sustainable use of the planet. Most important, failure to address these issues results in unsustainable use of resources and resource scarcity results in conflict.

\section{RESOURCE WARS}

Klare (2001) feels that much conflict results from the dependence of developed countries on the oil-rich Persian Gulf region and feels that the campaign against the Al-Qaeda and other terrorist networks is essentially a police action. There is little doubt that this theory enjoys overwhelming support from the international community. An overpowering military campaign, even if successful, might risk failing in the police action if too many civilian casualties occur and give the impression that this is an ethnic/religious war. Since Al-Qaeda is purported to be operating in as many as 60 countries (some Muslim) active cooperation in police and intelligence personnel will be required. Negative repercussions in even a few of these 60 countries, especially in the Muslim world, would impede these essential sources of information. Geography makes it difficult to separate police action and intelligence to minimize terrorist threats from the resource issue, but it may be essential if the military activity is prolonged in order to continue the police action and intelligence sharing for many years.

The sine qua non of sustainable use of the planet is an ecocentric utilization of resources. Resource wars will impede, if not negate, the quest for sustainability. To avoid intensified global resource wars, those countries using resources in the most profligate way should lead the transition to sustainability as an ethical imperative. Wealthy individuals should be willing to do the same, despite their ability to buy resources in an open market far in excess of the world average per capita consumption. Individuals may feel that they can afford large amounts of material goods and energy use, but Earth cannot afford such behavior. Perhaps the feeling of increased vulnerability, heightened by the events of 11 September 2001 and after, will increase individual and societal sensitivity to the plight of others who are already vulnerable as a result of poverty and other undesirable features of the human condition. This feeling should be bolstered by the recognition that those who are members of societies that feel hopeless are breeding grounds for terrorists.

\section{TERRORISM AND SUSTAINABILITY}

In the US and other developed countries, the present energy supply and delivery system is particularly vulnerable to terrorist attacks. Since 11 September, 'energy security' has been debated in the US as a national defense component. In October 2001, the US news media widely reported an incident when a single gunman fired several bullets into the Alaskan pipeline; one penetrated it. Containing the spillage of crude oil took three days and 100 workers. This occurence curtailed shipment of approximately $17 \%$ of the American oil production. Ironically, shifting to alternative energy sources, such as solar panels and windmills, would both reduce vulnerability to terrorist attacks on steam electric power plants and take a giant step toward sustainability.

If the 'war on terrorism' is drawn out over many years, prudent policy makers will surely consider the illustrative measures just discussed. If they do, the terrorists will have pushed society a significant distance on the road to sustainable use of the planet.

\section{ANALYSIS}

Baudrillard (2002) has provided a superb analysis of terrorism - like viruses, terrorists are ubiquitous with no boundary to hem them in. Baudrillard believes that every means of domination elicits its own antidote. In this context, nature might reasonably be regarded as the ultimate bioterrorist. Dominance by one species often temporarily results in vastly exceeding its resource base. This situation, in turn, exacerbates disease and famine, which are often accompanied by a substantial reduction of the resource base through overutilization. Arrogance resulting from dominance may give the illusion that factors that limit other species do not apply to the dominant group. Regrettably, this description fits a species that believes there is a cornucopia of natural resources on a finite planet and that it is not dependent upon the planet's ecological life support system.

Baudrillard (2002) astutely remarks that the globe itself is resistant to globalization. While focusing primarily on terrorist events within human society, the 
remark applies equally well to nature, which has a large array of diverse and constantly changing species (on an evolutionary time scale).

There is abundant evidence on the degree to which racism has been subsidized by many components of human society. Since the terrorist attacks on the World Trade Center and the Pentagon on 11 September 2001, the astonishing degree to which international terrorism has been subsidized is emerging. However, the degree to which speciesism is subsidized may well be larger than either racism or terrorism. Subsidies that harm the environment also harm large numbers of the planet's species. Using tax dollars to finance activities that harm other species is governmental speciesism. Myers \& Kent (1998) estimated the environmentally damaging subsidies total to be US\$1.9 trillion per year. They (Myers \& Kent 2001) recently raised the total to US\$2.5 trillion per year as a result of further analyses and stated that a more in-depth treatment would result in an even larger total. Hawken (1997) believes the worldwide total of environmentally damaging subsidies might even be as large as US\$10 trillion. All these authors provide persuasive arguments that ending these subsidies would benefit both the environment and the economy as well as other species. Arguably, eliminating environmentally damaging subsidies would benefit the human species and millions of others as well.

Why then has more not been done? In the US, at least, the answer is clear. Lawmakers practice 'pork barreling,' which means that elected officials garner funds from the public coffers to benefit their home districts. While the entire citizenry would not approve these projects, a small social component rejoices when persuaded it is getting more than its fair share. The net result, however, is an enormous waste of money because every member of the US Congress must at least give the appearance of bringing home some 'pork' to his/her district. The situation is even worse campaigns for reelection to the US House of Representatives is every two years, for the US Presidency every four years, and for the US Senate every six years. The reelection campaigns as presently carried out require huge sums of money, much of which comes from special interest groups that expect to be rewarded by special benefits, including direct or indirect subsidies. This lack of equity and fairness in the distribution of tax resources is not only bad for the environment but is also a fertile breeding ground for terrorists and racists. Terrorists may be trained in foreign countries but, to be a global threat, they must operate everywhere. This design requires a 'safe haven' in every country, which will be provided by those with a grudge against society. Both terrorism and racism divert and consume resources that otherwise could be used to improve the health and integrity of the planet's ecological life support system and improve the probability of achieving sustainability. Speciesism results from a failure to leave enough resources for them to flourish and, in all too many cases, to survive.

\section{CONCLUSIONS}

Sustainability would be difficult to achieve even in the absence of terrorism, racism, and speciesism; however, their reduction undoubtedly is an essential step toward sustainability. The means to achieving this goal is not immediately apparent, but it is so essential that a much more concerted effort is indispensable. If, as many think, global society is fast approaching critical ecological thresholds, time is short. Social evolution at a rapid pace unparalleled in history may be essential. However, exactly what course social evolution should take is far from clear. As a start, it would be prudent to diminish all clearly unsustainable practices, although how this can be done without seriously eroding individual freedom is unclear. An essential consideration for sustainability is that the alternative is unthinkable.

It may be arrogant to assume that one species, Homo sapiens, is capable of remaining on the planet indefinitely. The quest for sustainable use of the planet may merely be an elaborate form of denial that the human species cannot persist for the entire life of the planet, just as some people deny death by refusing to prepare personal wills. No matter how much violence humans do to their own species, it is improbable that humans can extinguish all life on the planet. Doubtless, there would be a rediversification of other species, especially if humans became either a relic species or extinct. In this scenario, it is worth considering how the human species should make its final exit. If humans cannot use the planet indefinitely, it would reflect well upon them if they left the planet in good shape for other life forms. Doubtless, other species would neither appreciate this gesture nor show gratitude for it, but humans would know that they acted with compassion rather than anger.

Nature's cybernetics are sometimes finely tuned, sometimes violent. Unquestionably, human society is engaged in an unprecedented global experiment for which the consequences are uncertain. Crossing multiple crucial ecological thresholds will not be immediately apparent because ecological health monitoring is far from robust and because ecological change often occurs in temporal spans not customary in societal decision making. By comparison the US anthrax scare (e.g. Cook 2001) is a comparatively minor risk, yet the economic consequences are already severe. Moreover, the earlier unshakable faith in the powers of technol- 
ogy to shield humankind from global risks is, at the very least, weakened. Clearly, environmentalists who grossly exaggerated damage (e.g. Lake Erie is dead) in the 1970s are partly to blame for this situation. If the possible, even probable, non-linear crossing of a crucial environmental threshold occurs and creates an environmental 'surprise,' one hopes the response will be a combination of changed societal behavior and development of appropriate technology. Terrorism, racism, and speciesism may well be the fatal obstacles to attaining a global societal ethos on which a mutualistic relationship between human society and natural systems can be based.

On an economic note, resistance to tax increases is strong, even in wealthy countries. As a consequence, diverting resources from destabilizing activities makes sense. Terrorism and racism are socially destabilizing, and speciesism is ecologically destabilizing; all result in the consumption of resources. However, it will be difficult to get these resources reallocated to sustainable use of the planet if the destabilizing activities are reduced. Persuasive evidence indicates a close link between human health and ecosystem health, even though it is difficult at present to quantify the economic benefits of ecosystem health. Compelling ethical reasons demand an increase in ecosystem health and integrity but, in the present value system of human society, economic values will almost certainly prevail.

However, there are hopeful case histories in this regard; Ellison (2002) reports that Allegheny Energy's calculation of the value of 12,000 acres it was selling to the US Fish and Wildlife Service included the value of the ecosystems. As a consequence of including the value of the land's ecosystems, the traditional estimates were more than doubled. Thus, there is at least some hope for a market-based conservation system.

Terrorism, racism, and speciesism must ultimately be judged by the ways in which they affect the interdependent web of life - the planet's ecological life support system. Actions that improve its health and strengthen its integrity have value, and those that diminish its health and integrity have no inherent worth (Cairns 2002). Leopold (1949) espoused the landscape viewpoint in his 'land ethic,' and Tansley (1935) also espoused the ecosystem concept in which organisms should be considered in the context of their chemical/physical/biological environment. The cult of 'rugged individualism' encourages the perspective that each person is somehow separate from the interdependent web of life. The view of Earth from space does not seem to have altered this perspective markedly. There is a persistent belief that human ancestors were different than present ones (e.g. Krech 1999; White 2000). Ehrlich (2000) notes that, about 50,000 years ago, human ancestors wiped out most of the Pleistocene megafauna, completely changing (possibly coupled with climate change) the biota of much of the planet. Diamond (1984) discusses the widespread absence of a conservation ethic in preindustrial humans. However, Wilson (2002) believes that ultimately, in a more democratic world, it will be the ethics and desires of the people, not their leaders, who give to or take away power from the government and the non-governmental organizations. Grishchenko (2001) states:

\begin{abstract}
There is not enough veneration, reverence, or worship towards the protection of nature. The consequences of human activity have become so serious, on such a global scale, that it is now impossible to simply shut nature away from civilization in an attempt to solve the problem by itself. Such an approach was reasonable about 200 years ago. Now, in many cases, it is necessary to compensate for these anthropogenic effects.
\end{abstract}

Acknowledgements. I am indebted to Sue Rasmussen for transferring the handwritten first draft of this manuscript to the word processor. Darla Donald provided her usual skilled editorial assistance. The Cairns Foundation paid for processing costs.

\section{LITERATURE CITED}

Baudrillard J (2002) L'esprit du terrorisme. Readings, Harpers Mag 304(1821):13-18

Cairns Jr J (1992) The threshold problem in ecotoxicology. Ecotoxicology 1:3-16

Cairns Jr J (1993) The intellectual electric fence. Annals of Earth XI(3):17-18

Cairns Jr J (1997) Defining goals and conditions for a sustainable world. Environ Health Persp 105(11):1164-1170

Cairns Jr J (1999) The diminished charge on the intellectual electric fence. The Social Contract IX(3):145-151

Cairns Jr J (2000) World peace and global sustainability. Int J Sustain Develop World Ecol 7:1-11

Cairns Jr J (2002) Reexamining 'the inherent worth and dignity of every person' paradigm in an interdependent web of life context. J Lib Rel 3(1), available at: www.meadville. edu/cairns_3_1.html

Callicott JB (2001) Multicultural environmental ethics. In: Tucker ME, Grim JA (eds) Religion and ecology: Can the climate change? Daedalus 130(4):77-97

Caldwell LK (1972) In defense of earth: international protection of the biosphere. Indiana University Press, Bloomington

Cook A (2001) Living with anthrax. BBC Letter from America, 29 Oct:09:38 GT

Darwin CR (1871) The decent of man and selection in relation to sex. J Murray Publishers, London

Diamond JM (1984) Historic extinctions: a Rosetta Stone for understanding prehistoric extinctions. In: Martin PS, Klein RD (eds) Quaternary extinctions: a prehistoric revolution. University of Arizona Press, Tucson, p 824-862

Dubos R (1972) A god within. Charles Scribner's Sons, New York

Durant W, Durant A (1968) The lessons of history. MJF Books, New York 
Ehrlich PR (2000) Human natures. Island Press, Washington DC Eisenberg E (1998) The ecology of Eden. Random House of Canada, Toronto

Eisley L (1970) The invisible pyramid. Charles Scribner's Sons, New York

Ellison K (2002) Land and eco-assets for sale: conservation joins capitalism to set aside wetland habitat. Washington Post 25 Jan:AO3

Emlen ST (1995) An evolutionary theory of the family. Proc US Nat Acad Sci 92:8092-8099

Freund P, Martin G (2001) Living with anthrax. BBC Letter from America 29 Oct 09:39GT

Grishchenko VN (2001) Forth ideology of nature reserves. Humanitarian Environ Mag 3(1):42-56 (in Russian); English Summary available at: www.esep.de/journals/esep/ esepnews.html

Hawken P (1997) Natural capitalism. Mother Jones MarApr:40-54

Hawken P, Lovins A, Lovins H (1999) Natural capitalism: creating the next industrial revolution. Little, Brown \& Co, New York

Hauser MD (2000) Wild minds: what animals really think. Henry Holt \& Co, New York

Kahneman D (1980) Human engineering of decisions. In: Kranzberg $M$ (ed) Ethics in an age of pervasive technology. Westview Press, Boulder, CO, p 190-192

Kellert SR, Wilson EO (eds) (1993) The Biophilia Hypothesis. Island Press, Washington DC

Klare MT (2001) Resources wars: the new landscape of global conflict. Metropolitan Books, New York

Krech III S (1999) The ecological Indian: myth and history. WW Norton, New York

Leopold A (1949) A Sand County almanac and sketches here and there. Oxford University Press, New York

Meadows D (2001) Computer predicts world collapse: author looks back on storm following book. The Social Contract $\mathrm{XI}(4): 231-232$

Meadows D, Meadows DH, Randers J (1992) Beyond the lim- its. Chelsea Green Publishing, Post Mills, VT

McNeill JR (2000) Something new under the sun: an environmental history of the twentieth-century world. WW Norton, London

Myers N, Kent JV (1998) Perverse subsidies: tax \$s undercutting our economies and environment alike. International Institute for Sustainable Development, Winnipeg, Manitoba

Myers N, Kent JV (2001) Perverse subsidies: how tax dollars can undercut the environment and the economy. Island Press, Washington, DC

Orvos DR, Cairns Jr J (1998) Estimating the risks associated with implementing goals and conditions for global sustainability. Int J Sustainable Dev World Ecol 5:13-163

Pulliam HR (1988) Sources, sinks, and population regulation. Am Nat 132:652-661

Rowe S (1999/2000a) Review of The ecology of eden. The Structurist 39/40:77-81

Rowe S (1999/2000b) Review of Consilience. The Structurist 39/40:82-85

Tansley AG (1935) The use and abuse of vegetational concepts and terms. Ecology 16:284-307

Tucker ME, Grim JA (eds) (2001) Religion and ecology: Can the climate change? Daedalus 130(4):306

Wackernagel M, Rees W (1996) Our ecological footprint. New Society Publishers, Gabriola Island, British Columbia

Ward B (1973) Speech for Stockholm. In: Strong MF (ed) Who speaks for earth? WW Norton, New York, p 19-31

White R (2000) Dead certainties. The New Republic 24 Jan: 44-49

Wilson EO (1984) Biophilia. Harvard University Press, Cambridge, MA

Wilson EO (1998) Consilience: the unity of knowledge. Alfred A. Knopf, New York

Wilson EO (2002) The future of life. Alfred A. Knopf, New York

World Commission on Environment and Development (1987) Our common future. Oxford University Press, New York

Submitted: November 21, 2002; Accepted: November 26, 2002 Proofs received from author(s): December 2, 2002 Published on the web: December 3, 2002
Editorial responsibility: Mary Batson (Managing Editor) Oldendorf/Luhe, Germany 